\title{
PERKEMBANGAN FEMINISME BARAT \\ DARI ABAD KEDELAPAN BELAS HINGGA POSTFEMINISME: SEBUAH TINJAUAN TEORETIS
}

\author{
Ni Komang Arie Suwastini \\ Jurusan Pendidikan Bahasa Inggris \\ Universitas Pendidikan Ganesha \\ Singaraja, Indonesia
}

Email: ariesuwastini 101004@yahoo.co.uk

\begin{abstract}
Abstrak
Tulisan ini mengulas perkembangan feminisme barat dari abad ke delapan belas hingga abad ke dua puluh satu saat feminisme memasuki era postfeminisme untuk mengungkapkan perubahan feminisme dari waktu ke waktu merupakan perkembangan yang menunjukkan kemampuan feminisme untuk menyesuaikan diri dengan tuntutan situasi dan kondisi yang dialami perempuan. Dalam garis besar, feminisme dapat dibagi menjadi empat tonggak perkembangan, yakni feminisme awal, feminisme gelombang pertama, feminisme gelombang kedua, dan feminisme gelombang ketiga dan/atau postfeminisme. Secara umum keempatnya memiliki tujuan yang sama yakni untuk memperjuangkan subjektivitas perempuan Masing-masing gelombang memiliki penekanan perjuangan yang berbeda dan setiap gelombang berikutnya merupakan revisi dari gelombang sebelumnya. Dikotomi feminisme gelombang ketiga dan/atau postfeminisme merupakan perkembangan yang paling majemuk dan menimbulkan banyak kontroversi karena postfeminisme merupakan persinggungan antara feminisme dan postmodernisme yang berkembang menjelang pergantian milennium yang berpadu dengan kebutuhan internal dalam feminisme sendiri. Kemajemukan dalam perkembangan feminisme terakhir ini harus dipandang sebagai kekayaan dan kelebihan karena itu berarti feminisme semakin terbuka terhadap perbedaan dan perubahan.
\end{abstract}

Kata Kunci: Feminisme, postfeminisme, subjektivitas.

\begin{abstract}
The present paper aims at review the development of western feminism from the eighteenth century up to the twenty-first century when feminism entered the era of postfeminism in order to demonstrate that the developments of feminism is a continuous process which shows feminism's adaptability to women's contemporary issues. In the broadest sense, feminism can be periodically divided into four stages of development, namely the early feminism, the first-wave feminism, the second-wave feminism, and the third-wave feminism and/or postfeminism. In general they all share the same goal that is to promote female subjectivity with different emphases in their goals and each subsequent wave is a revision of the proceeding wave. Third-wave feminism and/or postfeminism, however, is the most plural and controversial development as it is the intersection between feminism with the postmodern paradigms that develops robustly before the turn of the millennium combined with the internal demands from within feminism. The pluralism in this last stage of feminism should be considered as strength for feminism as it shows feminism's adaptability to diversity and change.
\end{abstract}

Key Words: feminism, postfeminism, subjectivity 


\section{PENDAHULUAN}

Setelah feminisme gelombang kedua mencapai puncaknya pada tahun 1970an, terjadi perkembangan yang meresahkan kaum feminis baik dari pihak akademis maupun pihak praktisi. Pada 1980an, berkembang banyak aliran feminisme yang berbeda dan sering berkontradiksi satu sama lainnya. Salah satu perkembangan yang paling meresahkan adalah perkembangan postfeminisme yang sering diartikan sebagai matinya feminisme. Tulisan berikut akan membahas pengertian feminisme dan tahapan-tahapan perkembangannya, diikuti dengan pengertian postfeminisme dan prinsipprinsipnya untuk menunjukkan bahwa postfeminisme merupakan kelanjutan dari feminisme itu sendiri.

Sarah Gamble memberikan definisi umum feminisme sebagai "the belief that women, purely and simply because they are women, are treated inequitably within a society which is organized to prioritise male viewpoints and concerns" (2006: vii). Feminisme adalah paham, kajian, dan gerakan sosial yang bertujuan untuk mengubah status subordinat perempuan dalam masyarakat yang mengutamakan perspektif laki-laki. Masyarakat yang mengutamakan kepentingan laki-laki di atas kepentingan perempuan merupakan definisi dari masyarakat yang patriarkis (Weedon, 1987 dalam Hodgson-Wright, 2006: 3).

Feminisme merupakan perjuangan untuk mengakhiri penindasan terhadap perempuan (Jenainati dan Groves, 2007: 3). Sejalan dengan Jenainati dan Groves, Ross (2009) melihat feminisme sebagai semua usaha yang bertujuan untuk memperbaiki kondisi perempuan. Dengan mengaitkan definisi umum feminisme dari Gamble (2006), Jenainati dan Groves (2007) dan Weedon (1987), feminisme dapat dirumuskan sebagai keyakinan, gerakan dan usaha untuk memperjuangkan kesetaraan posisi perempuan dan laki-laki dalam masyarakat yang bersifat patriarkis.
Namun perlu diingat bahwa feminisme bukanlah gerakan universal dengan konsep homogen yang dapat mewakili seluruh perempuan. Seperti yang ditekankan Tong (2009), feminisme merupakan konsep yang sangat luas dan majemuk. Feminisme merupakan sebuah kata yang memayungi berbagai pendekatan, pandangan, dan kerangka berpikir yang digunakan untuk menjelaskan penindasan terhadap perempuan dan jalan keluar yang digunakan untuk meruntuhkan penindasan tersebut (Tong, 2009: 1). Adapun pembagian feminisme menjadi gerakan feminisme awal, feminisme gelombang kedua, dan feminisme gelombang ketiga seperti yang dilakukan Gamble (2006) merupakan salah satu usaha untuk menarik benang merah perkembangan feminisme secara kronologis.

\section{GERAKAN FEMINISME AWAL}

Gerakan feminisme awal merupakan sebagai usaha-usaha untuk menghadapi patrarki antara tahun 15501700 di Inggris (Hodgson-Wright, 2006). Fokus perjuangan feminisme awal adalah melawan pandangan patriarkis mengenai posisi subordinat perempuan karena dianggap sebagai mahluk yang lebih lemah, lebih emosional dan tidak rasional (Jenainati dan Groves, 2007: 9). Pemikiran ini dimungkinkan karena berkembangnya Pencerahan di Inggirs yang mempengaruhi pemikiran mengenai perempuan sebagai bagian dari masyarakat yang turut berperan bagi perkembangan masyarakat (O'Brien, 2009).

Menurut Hodgson-Wright (2006), perjuangan feminisme awal melalui tiga cara. Pertama melalui usaha untuk merevisi esensials subordinasi perempuan dalam ajaran gereja. Kedua dengan menentang berbagai buku panduan bersikap yang cenderung mengekang perempuan pada jaman tersebut. Ketiga, dengan membangun solidaritas antar penulis perempuan. Solidaritas ini membangun kepercayaan diri dan dukungan finansial di kalangan penulis 
perempuan. Pendidikan inteketual yang diberikan kepada anak-anak perempuan dalam keluarga-keluarga yang dipengaruhi oleh Pencerahan pada gilirannya menerbitkan inspirasi mengenai pentinganya pendidikan perempuan menjadi dasar bagi pergerakan yang lebih politis dalam feminisme gelombang pertama (Ross, 2009).

\section{FEMINISME GELOMBANG PERTAMA}

Feminisme gelombang pertama dianggap dimulai dengan tulisan Mary Wollstonecraft The Vindication of the Rights of Woman (1792) hingga perempuan mencapai hak pilih pada awal abad keduapuluh (Sanders, 2006). Tulisan Wolstonecraft dilihat Sanders sebagai tonggak gerakan feminisme modern Wollstonecraft menyerukan pengembangan sisi rasional pada perempuan dan menuntut agar anak perempuan dapat belajar di sekolah pemerintah dalam kesetaraan dengan anak laki-laki. Pendidikan ini diharapkan Wolstonecfrat akan mengembangkan intelektualitas perempuan sehingga mampu berkembang menjadi individu yang mandiri, terutama secara finansial (Richardson, 2002). Perjuangan Wollstonecraft dilanjutkan oleh pasangan Harriet dan John Stuart Mill. Mereka memperjuangkan perluasan kesempatan kerja bagi perempuan dan hak-hak legal perempuan dalam pernikahan maupun perceraian.

Feminisme gelombang pertama juga sudah diwarnai oleh usaha beberapa perempuan untuk memperjuangkan hak perempuan setelah menikah dan hak asuh anak setelah perceraian. Salah satu pejuang hak perempuan yang sudah menikah yang paling menonjol adalah Caroline Norton yang memperjuangkan hak asuh atas anakanaknya setelah Caroline bercerai (Gleadle, 2002). Aktifitas para perempuan ini merangsang tumbuhnya kesadaran mengenai ketertindasan perempuan yang kemudian mendorong munculnya berbagai organisasi untuk membela nasib kaum perempuan. Aktifitas kaum feminis di Inggris ini bergaung juga di Amerika yang mencapai tonggak penting pada Seneca Falls Convention (1848) yang menuntut dihapuskannya semua diskriminasi berdasarkan jenis kelamin.

Di Inggris, meningkatnya meningkatnya jumlah perempuan yang bekerja menuntut disediakannya sekolah yang dapat mempersiapkan perempuan sebagai tenaga kerja professional. Meski lapangan kerja yang tersedia umumnya berada pada sektor domestik, namun hal ini mendorong meluasnya kebutuhan pendidikan untuk perempuan. Pada gilirannya, semakin banyak perempuan yang terlibat di dunia pendidikan yang memicu dicetuskannya ide bahwa perempuan berhak mendapatkan hak pilih (Sanders, 2006). Isu ini semakin memuncak pada 1895 saat kata "feminist" digunakan untuk pertama kalinya dalam Athenaeum (Walters, 2005: 1). Hak pilih untuk perempuan dicapai pada 1918 .

Menurut Sanders (2006), feminisme gelombang pertama mencakup beberapa ambivalensi. Para feminis gelombang pertama sangat berhati-hati agar tidak terlibat kehidupan yang tidak konvensional. Mungkin ini ada kaitannya dengan backlash yang dialami pasca biografi Mary Wollstonecraft (Kirkham, 1997). Di samping itu, gerakan ini hanya memperjuangkan perempuan lajang dari kelas menengah saja, terutama yang memiliki intelektualitas tinggi. Sementara itu, gerakan mereka hanya ditujukan untuk isu-isu tertentu saja dan belum ada kesadaran mengenai gerakan feminisme yang lebih luas. Hanya perempuan kaya yang memiliki kesempatan untuk berkarir dan kehidupan domestic karena mereka mampu membayar pelayan untuk melakukan pekerjaan rumah tangga mereka. Dan kritik yang paling mencolok adalah para feminis ini masih mengandalkan bantuan kaum laki-laki untuk mencapai tujuan-tujuan mereka.

\section{FEMINISME GELOMBANG KEDUA}


Feminisme gelombang kedua dimulai pada tahun 1960an yang ditandai dengan terbitnya The Feminine Mystique (Freidan, 1963), diikuti dengan berdirinya National Organization for Woman (NOW, 1966) dan munculnya kelompok-kelompok conscious raising (CR) pada akhir tahun 1960an (Thompson, 2010). Feminisme gelombang kedua dinilai sebagai feminisme yang paling kompak dalam paham dan pergerakan mereka (Thornham, 2006). Feminisme gelombang kedua bertema besar "women's liberation" yang dianggap sebagai gerakan kolektif yang revolusionis. Gelombang ini muncul sebagai reaksi ketidakpuasan perempuan atas berbagai diskriminasi yang mereka alami meskipun emansipasi secara hukum dan politis telah dicapai oleh feminisme gelombang pertama. Untuk itu, feminisme gelombang kedua lebih memusatkan diri pada isu-isu yang mempengaruhi hidup perempuan secara langsung: reproduksi, pengasuhan anak, kekerasan seksual, seksualitas perempuan, dan masalah domestisitas (Gillis, et.al., 2004).

Menurut Thornham (2006), feminisme gelombang kedua di Amerika dapat dikelompokkan menjadi dua aliran. Kelompok pertama merupakan aliran kanan yang cenderung bersifat liberal yang bertujuan untuk memperjuangkan partisipasi perempuan di seluruh kehidupan sosial (di Amerika), dengan hak dan kewajiban yang sama dengan laki-laki. Aliran ini ada di bawah organisasi NOW (National Organization for Women- Organisasi Perempuan Nasional) yang didirikan oleh Betty Freidan pada 1966.

Aliran kedua sering disebut aliran kiri dan bersifat lebih radikal. Feminisme radikal berakar reaksi para feminis yang merasa tidak terfasilitasi dalam feminisme liberal NOW karena perbedaan ras, kelas, dan protes terhadap kekejaman Amerika dalam perang Vietnam (Siegel, 2007). Konsep utama feminisme radikal adalah "consciousness raising' dengan paham "the personal is political" (Whelehan, 1995).
Paham ini percaya bahwa kekuasaan patriarki bekerja pada insitusi-institusi personal seperti pernikahan, pengasuhan anak, dan kehidupan seksual (Genz dan Brabon, 2009: 48). Menurut aliran ini, perempuan telah dipaksa oleh patriarki untuk bersikap apolitis, mengalah, dan lemah kembut. Mereka menentang konteskontes kecantikan karena menganggap kontes-kontes tersebut sebagai sarana untuk mencekoki perempuan dengan standar kecantikan yang melemahkan posisi perempuan.

Di Inggris, Kelompok Kanan terbentuk kuat di kalangan perempuan pekerja. Mereka melaksanakan pemogokan untuk menuntut persamaan upah. Sementara itu kelompok kiri sangat dipengaruhi oleh paham Sosialis Marxisme (Thornham, 2006). Namun dalam The British National Women's Liberation Conference pada 1970, aliran kanan dan kiri di Inggris bersatu dan menyerukan satu feminisme. Secara kompak mereka menuntut persamaan upah, persamaan pendidikan dan kesempatan kerja, tempat penitipan anak 24 jam, alat kontrasepsi gratis, dan aborsi sesuai kebutuhan. Tuntutan-tuntutan ini menunjukan bahwa feminisme gelombang kedua berfokus pada isu perempeuan sebagai kelompok yang tertindas dan tubuh perempuan sebagai situs utama penindasan tersebut.

Menurut Thornham (2006), salah satu ciri utama feminisme gelombang kedua baik di Inggris maupun di Amerika adalah usaha mereka untuk merumuskan teori yang mampu memayungi semua perjuangan feminis. Dalam pandangan Thornham, buku The Second Sex (1956) dari Simone de Beauvoir menjadi salah satu acuan utama feminisme tahun 1970an. Simone de Beauvoir menentang determinisme biologis dalam fisiologi, determinisme dorongan bawah sadar dalam psikoanalisa Freud dan determinisme subordinasi ekonomi dalam teori Marx (Phoca dan Wright, 1999; Thornham, 2006). Menurut de Beauviour, teori-teori tersebut telah mendorong 
internalisasi konsep perempuan sebagai yang liyan (the Other) dan perempuan menjadi wanita karena konstruksi-konstruksi sosial yang patriarkis tersebut (de Beauvoir, 1956). Bagi de Beauvoir, perempuan harus merebut kesempatan untuk mencapai kesetaraan dalam hal ekonomi dan sosial agar perempuan menjadi subjek yang setara dengan laki-laki.

Di Amerika, pendapat de Beauvoir dikembangkan oleh Betty Freidan, Kate Millett, dan Shulamith Firestone (Jenainati dan Groves, 2007). Baik Freidan maupun de Beauvoir percaya bahwa satu-satunya jalan untuk membebaskan perempuan dari ketertindasan adalah dengan mengubah perempuan itu sendiri. Freidan berpendapat, untuk menjadi perempuan yang setara dengan laki-laki, perempuan harus meninggalkan jebakan rumah tangga dan semua "feminine mystique" yang mengikat perempuan dalam konstuksi yang mensubordinasinya (Freidan, 1963).

Menurut feminis gelombang kedua, conscious rising (pencerahan akan kondisi tertindasnya perempuan oleh patriarki) merupakan alternative terbaik untuk menyadarkan perempuan dari keterkungkuan mereka (O'Reilly dan Porter, 2005). Sementara itu Kate Millett dan Firestone berpendapat lebih radikal. Bergerak di bidang sastra, Kate Millett mengembangkan kajian sastra, film, dan budaya untuk melawan penindasan terstruktur melalui control ideologis. Sementara Firestone mengikuti ajaran Marxis dan mengajak perempuan menguasai alat-alat reproduksi (Tong, 2009).

Di Inggris, Julliet Mitchel setuju bahwa penindasan perempuan utamanya dilakukan secara ideologis dalam 'psychology of femininity' (Thornham, 2006). Diinternalisasi oleh perempuan melalui pencekokan ideologi yang terstruktur, psikologi femininitas ini kemudian diwujudkan dalam perilaku seksual yang privat dan pengabdian pada keluarga. Namun tidak seperti Firestone, Mitchel berpendapat pembebasan perempuan terletak pada penguasaan control terhadap produksi, reproduksi, seksualitas, dan pendidikan anak (Tong, 2009).

Di Perancis, Luce Irigaray, Hélène Cixous dan Julia Kristeva menggunakan psikoanalisa untuk menjelaskan subordinasi posisi perempuan (Tong, 2009). Ketiganya setuju dengan de Beauvoir bahwa perempuan menginternalisasi peran mereka sebagai yang liyan. Dengan menggunakan psikoanalisa dari Lacan, mereka menelusuri subordinasi perempuan melalui perbedaan seksual yang dikonstruksi dalam bahasa dan budaya (Thornham, 2006).

Feminisme gelombang kedua dikritisi oleh para perempuan kulit hitam, lesbian, dan perempuan pekerja yang kemudian membentuk gerakan radical (Gubar, 2000; Jenainati dan Groves, 2007). Banyak pihak yang menganggap "women's liberation" hanya mengutamakan perempuan kulit putih dan gagal mencakup isu kelas dan ras (Zaslow, 2009: 28), meski Thompson (2010) berpendapat feminisme sejak awal selalu dipengaruhi oleh isu mengenai perempuan Afrika, Latina, dan Asia. Sementara itu, kaum lesbian menuduh feminisme gelombang kedua mengutamakan kaum heteroseksual dan mengesampingkan lesbianisme (Thornham, 2006), meski Whelehan (1995) dan Tong (2009) menunjukkan bahwa femininisme radikal dan feminisme lesbian berkembang secara simultan pada 1960an dan 1970an.

Secara umum, teori-teori feminis gelombang kedua dianggap "setengah ramalan setengah utopia (Bammer, 1991). Terlepas dari rasa solidaritas yang terbangun antar feminis gelombang kedua, selalu ada perbedaan antara perempuan dari berbagai kelas, ras, dan etnis. Karena itu, pencarian terhadap feminisme yang mampu mewakili seluruh perempuan merupakan sebuah utopia (Braidotti, 2003: 197), karena feminisme berakar dari berbagai isu yang berbeda dan karenanya memiliki sejarah dan perkembangan yang 
majemuk (Whelehan, 1995; Gubar, 2000; Tong, 2009; Budgeon, 2011a).

Kenyataan mengenai perbedaan mendorong perkembangan feminisme ke berbagai arah yang berbeda. Feminisme gelombang kedua dianggap berakhir pada 1975 (Hewitt, 2010) dan pada akhir 1980an, feminisme berkembang secara divergen ke arah feminisme gelombang ketiga dan yang berbarengan dengan lahirnya postfeminisme yang kontroversial.

\section{POSTFEMINISME/FEMINISME GELOMBANG KETIGA}

Berbagai kritik terhadap

universalisme dalam feminisme gelombang kedua mendorong terjadinya pendefinisian kembali berbagai konsep dalam feminisme pada akhir tahun 1980an. Menurut Brooks (1997: 8), setidaknya ada tiga hal yang mendorong terjadinya reartikulasi konsepkonsep feminisme. Pertama, dari dalam feminisme sendiri yang mulai melihat bahwa konsep mereka bersifat rasis dan etnosentris yang hanya mewakili perempuan kulit putih kelas menengah dan memarginalkan perempuan dari kelompok etnis dan kelas lainnya. Kedua, feminis gelombang kedua dianggap belum cukup menyuarakan isu "sexual difference." Sementara itu, di luar feminisme, berkembang teori-teori postmodenrnisme, poststrukturalisme dan postkolonialisme yang kemudian beririsan dengan perkembangan feminisme.

Dengan sedemikian banyaknya suara yang tak terwakili dalam feminisme gelombang kedua berpadu dengan perkembangan post-modernisme, perkembangan feminisme sejak akhir tahun 1980an menjadi sangat majemuk. Postmodernisme menolak wacana monolitik dan kebenaran tunggal serta pengaburan batas-batas adi budaya dengan budaya masa (dalam hal ini budaya populer). Dengan konsep-konsep postmodernis ini, banyak suara yang tadinya dipinggirkan mendapatkan kesempatan untuk menyuarakan diri dan didengar. Hal ini mengakibatkan begitu banyak aliran yang dapat dicakup dalam perkembangan feminisme pasca gelombang kedua.

Dikotomi antara feminisme gelombang ketiga dan postfeminisme dalam perkembangan feminisme pasca gelombang kedua merupakan salah satu permasalahan mendasar yang dialami mengenai penamaan perkembangan feminisme pasca 1970an. Jika keduanya dianggap sebagai perkembangan feminisme yang berbeda, maka keduanya merupakan perkembangan yang berlangsung pada waktu yang hampir bersamaan. Jika keduanya dianggap perkembangan yang sama, ada usahausaha definitif dari beberapa feminis yang mendefinisikan diri mereka sebagai feminis gelombang ketiga dan atau sebaliknya postfeminist. Lebih jauh, kedua istilah tidak hanya sering dimaknai secara bertentangan, keduanya juga memiliki banyak definisi yang terkadang saling tumpang tindih dan saling bertentangan.

Istilah postfeminisme muncul lebih awal dalam sebuah artikel pada 1920. Istilah ini digunakan untuk menyatakan sikap "pro perempuan namun tidak anti-laki-laki," yang merayakan keberhasilan feminisme gelombang pertama dalam meraih hak pilih (Faludi, 2006; Genz dan Brabon: 2009).

Istilah postfeminisme kembali muncul pada 1980an dengan makna yang sangat beragam. Gill dan Scharff (2011) merangkum adanya empat pengertian postfeminisme. Pertama, postfeminisme sebagai titik temu antara feminisme dengan postmodernisme, poststrukturalisme, dan postkolonialisme yang berarti postfeminisme merupakan pengkajian yang lebih kritis terhadap feminisme (Brooks, 1997).

Pengertian postfeminisme berikutnya mengacu pada perayaan matinya feminisme yang ditandainya dengan tercapainya tujuan-tujuan feminisme gelombang kedua pada 1970an sehingga tujuan-tujuan tersebut tidak lagi relevan pada 1980an (Tasker dan Negra, 2007 dikutip dalam Gill dan Scharff, 2011). Pengertian post-feminisme sebagai perayaan atas matinya feminisme ini 
diajukan oleh para pendukung feminisme gelombang kedua. Tania Modleski, misalnya, melihat postfeminisme sebagai kajian yang menegasi dan meruntuhkan perjuangan kaum feminis dan mengantar perempuan kembali ke jaman pre-feminis (dikutip dalam Gamble, 2006: 37).

Pengertian postfeminisme yang ketiga menurut Gill dan Scharff (2011) adalah postfeminisme sebagai backlash. Susan Faludi merupakan salah satu proponen utama perumusan definisi postfeminisme sebagai backlash. Dalam buku fenomenalnya Backlash: The Undeclared War Against American Women (1991), Faludi merumuskan postfeminisme sebagai perang terhadap feminisme melalui media masa dan budaya popular. Media masa dan budaya popular digunakan sebagai perantara untuk menyebarkan propaganda yang mendiskreditkan perempuan-perempuan yang telah teremansipasi. Backlash, menurut Faludi, mendapat dukungan dari pemerintah (2006: 291).

Definisi postfeminisme keempat yang dirangkum Gill dan Scharff (2011) adalah postfeminisme sebagai sensibility. Dengan mengacu pada pembahasan terhadap konsep "double entanglement" dari Judith Butler yang dilakukan oleh McRobbie (1994, 2009), postfeminisme merupakan "both a doing and undoing of feminism" yang mengartikulasikan konsep-konsep feminisme pendahulunya sekaligus melakukan peninjauan kembali atas konsepkonsep tersebut. Salah satu konsep feminis yang mengalami redefinisi adalah peralihan femininitas sebagai bagian dari tubuh dan perubahan focus dari objektifikasi perempuan ke subjektifikasi yang lebih menekankan pada kemampuan perempuan untuk membuat keputusan, pilihan, dan mempertanggungjawabkan diri sendiri.

Feminisme gelombang ketiga juga memiliki banyak definisi yang berbeda dan terkadang saling bertentangan. Para pencetus feminisme gelombang ketiga secara sistematis menyatakan diri mereka sebagai reaksi atas postfeminisme. Mereka memiliki pandangan negatif terhadap postfeminisme. Para pelopor feminisme gelombang ketiga seperti lyvonne Tasker dan Diane Negra memiliki pandangan negatif terhadap postfeminisme dan menarik dikotomi antara feminisme gelombang ketiga dan postfeminisme dalam hubungannya dengan budaya popular (Genz dan Brabon, 2009). Postfeminisme dinilai sebagai feminisme aras utama yang dimotori berbagai kepentingan komersial tanpa aktivitas ataupun agenda feminis yang jelas. Dalam hal ini, feminisme gelombang ketiga menyatakan diri sebagai feminisme yang berkembang di dunia akademik, bersifat sistematis, dan bersifat lebih kritis.

Gamble (2006) melihat feminisme gelombang ketiga sebagai reaksi perempuan kulit berwarna terhadap dominasi perempuan kulit putih dalam feminisme gelombang kedua dan menolak asumsi bahwa penindasan terhadap perempuan bersifat seragam dan universal. Lebih jauh, feminisme gelombang ketiga juga terlibat berbagai aktivitas turun ke jalan. Gamble menyerukan penggunaan istilah feminisme gelombang ketiga dan menolak penggunaan istilah postfeminisme karena implikasi negatif yang melekat pada makna postfeminisme.

Tong (2009) mendefinisikan feminisme gelombang ketiga sebagai perkembangan feminisme yang dimulai pada 1990an yang mendapat pengaruh dari feminisme-feminisme sebelumnya. Feminisme ini, lanjut Tong, memiliki rumusan agenda feminisme yang berbeda dari feminisme pendahulunya karena feminisme gelombang ketiga merayakan perbedaan (2009: 271). Berbeda dengan Gamble yang menentang istilah postfeminisme, Tong bahkan menolak untuk menyebut istilah postfeminisme dan memilih menggunakan istilah feminisme multicultural.

Shelley Budgeon (2011a) melihat feminisme gelombang ketiga sebagai feminisme yang sangat dipengaruhi oleh 
budaya populer. Hal ini bertentangan dengan pendapat Tasker dan Negra serta pendapat Faludi di atas yang melihat posteminisme sebagai feminisme yang merangkul budaya populer. Bagi Budgeon, feminisme gelombang ketiga melihat budaya populer sebagai objek kajian kritis dan menolak oposisi biner yang memarginalkan budaya populer (2011a: 280). Feminisme gelombang ketiga merupakan perkembangan feminisme yang mendekonstruksi dan mengevaluasi kembali feminisme sebelumnya agar dapat terus berkembang dan memfasilitasi perempuan pasca feminisme tahun 1970an (Budgeon, 2011b: 4).

Di sisi lain, Budgeon mendefinisikan postfeminisme sebagai perkembangan feminisme yang lebih kontradiktif terhadap feminisme gelombang kedua. Dalam pandangan Budgeon, postfeminisme merangkul sekaligus menolak feminisme. Budgeon sepakat dengan Angela McRobie yang melihat postfeminisme sebagai perayaan terhadap pencapaian tujuantujuan feminisme sehingga feminisme dapat dilihat sebagai masa lalu (McRobbie, 2009). Tercapainya tujuan-tujuan feminisme membuka jalan bagi perempuan untuk mencapai tujuan-tujuan yang bersifat individual melalui gaya hidup dan pola konsumsi yang menjadi ciri khas postfeminisme (2011b: 281). Jadi, dalam pemahaman Budgeon dan McRobbie, feminisme gelombang ketiga bersifat global, aktifis, dan akademis sementara postfeminisme lebih bersifat individualistic, konsumtif, dan populer.

Zeisler (2008) melihat feminisme gelombang ketiga sebagai istilah yang memayungi berbagai perkembangan feminisme pasca gelombang kedua dengan berbagai definisi yang saling bertentangan. Sementara itu, postfeminisme dilihat sebagai bentuk protes dari generasi feminis non-akademis yang melihat feminisme sebagai gerakan yang sudah mencapai tujuannya dan karenanya sudah tidak relevan lagi untuk dilanjutkan. Menurut
Zeisler, kemajemukan definisi feminisme gelombang ketiga disebabkan karena masing-masing pelopornya berusaha merumuskan gelombang feminisme ini menurut pengalaman individual atau kelompok semata (2008: 113). Dalam hal ini, Zeisler melihat feminisme gelombang ketiga sebagai perkembangan feminisme yang lebih individual yang antara lain disebabkan karena kegagalan feminisme gelombang kedua untuk memfasilitasi kemajemukan dalam rumusan feminisme hegemonis mereka.

Bertentangan dengan Zeisler, Brooks melihat postfeminisme sebagai istilah yang memayungi berbagai perkembangan feminisme pasca 1970an. Menurut Brooks, postfeminisme merupakan "a [sic] conceptual frame of reference encompassing the intersection of feminism with a number of antifoundationalist movements [sic] represent[ing] feminism 'coming of age,' its maturity into a confident body of theory and politics, representing pluralism and difference and reflecting on its position in relation to other philosophical and political movements similarly demanding change". (Brooks, 1997: 1)

Definisi ini tidak menafikan gerakangerakan feminisme terdahulunya dan melihat postfeminisme sebagai perkembangan feminisme dipengaruhi oleh perkembangan berbagai bidang lainnya. Dengan pengaruh berbagai teori dan gerakan anti-fundalis yang mengakui kemajemukan dan perbedaan, definisi mengakui adanya berbagai aliran dalam perkembangan feminisme. Dengan sikap terbuka terhadap perkembangan di dunia filsafat dan dunia politik, definisi postfeminisme ini bisa menerima berbagai perubahan dan perkembangan yang terjadi pasca feminisme gelombang kedua, baik yang bersifat teoretis maupun bersifat populer.

Namun terlepas dari berbagai kontradiksi dalam pendefinisian feminisme pasca gelombang ketiga, Genz dan Brabon 
melihat bahwa feminisme gelombang ketiga maupun postfeminisme memiliki banyak persamaan. Bahkan keduanya sering digunakan sebagai istilah yang memayungi seluruh perkembangan feminisme pasca 1970an. Misalnya saja Brooks (1997) serta Genz dan Brabon (2009) menggunakan istilah postfeminisme untuk mencakup feminisme gelombang ketiga, sementara Zaslow (2009) dan Budgeon (2011) menggunakan feminisme gelombang ketiga untuk mencakup postfeminisme. Keduanya menentang agenda anti budaya populer dalam feminisme gelombang kedua dan mengakui budaya populer sebagai situs yang subur untuk mengartikulasikan feminisme dan pemberdayaan perempuan (Genz dan Brabon, 2009: 162). Dan dengan berpegang pada rumusan postfeminisme yang diusulkan Brooks (1997) serta Genz dan Brabon (2009), keduanya dipengaruhi oleh teori-teori postmodern dan keduanya merangkul perbedaan.

Pada akhirnya, usaha untuk membedakan postfeminisme dan feminisme gelombang ketiga dianggap sia-sia karena menurut Gamble, "any attempt to differentiate between third wave feminism and postfeminism may be achieving nothing more than a little juggling with semantics" (2006: 44). Menurut Genz dan Brabon, perbedaan antara postfeminisme dengan feminisme gelombang ketiga fenomenon yang tak terhindarkan dari kehidupan sosial budaya masyarakat Barat yang rentan terhadap kontradiksi (2009: 162). Meski pendapat ini cenderung menggaris bawahi feminisme gelombang ketiga sebagai perkembangan yang didominasi dunia Barat, namun kesadaran feminisme untuk mengakui perbedaan dan merangkul kemajemukan menjadi modal sendiri bagi perempuan non-Barat untuk mengembangkan feminisme dengan keyakinan bahwa feminisme pasca gelombang kedua berkomitmen untuk merangkul aliran-aliran feminis yang berbeda.

\section{KESIMPULAN}

Dari pembahasan di atas, dapat dilihat bahwa feminisme telah berkembang dari sekedar perjuangan untuk diakui sebagai manusia yang memiliki rasio seperti layaknya laki-laki, feminisme berkembang menjadi gerakan yang memiliki aspirasi majemuk. Namun inti dari kesemua perjuangan tersebut adalah kesetaraan perempuan untuk menjadi subjek aktif dalam hidupnya. Masing-masing gelombang memiliki penekanan yang berbeda dalam tujuan periodiknya. Tujuan feminisme awal berevolusi dari perjuangan untuk diterima sebagai mahluk yang berasio menjadi tuntutan atas hak-hak perempuan yang lebih legal. Feminisme gelombang pertama berawal dari tuntutan yang sama atas pendidikan bertujuan untuk memperjuangkan hak perempuan untuk mendapatkan pendidikan formal berevolusi menjadi tuntutan untuk mendapatkan hak pilih. Kesetaraan dalam segala bidang dalam feminisme gelombang kedua kemudian berevolusi menjadi tuntutan atas hak-hak istimewa perempuan karena fisiologisnya yang berbeda dari laki-laki. Sedangkan feminisme gelombang ketiga dan/atau postfeminisme telah memiliki agenda yang sangat majemuk sejak awal dimulainya.

Perubahan dalam feminisme dari waktu ke waktu maupun kemajemukan feminisme pasca 1970an bukanlah sebuah kelemahan. Perubahan dalam tujuan-tujuan feminisme merupakan bukti bahwa feminisme dapat beradaptasi terhadap perubahan kebutuhan perempuan sesuai dengan tuntuan jaman yang dihadapi perempuan. Sedangkan kemajemukan dalam feminisme pasca gelombang kedua bukanlah hal yang baru bagi feminisme. Menurut Tong (2009), feminisme merupakan gerakan yang memiliki akar majemuk. Berbagai aliran yang muncul dalam feminisme, baik dalam feminisme gelombang kedua maupun gelombang ketiga merupakan perkembangan dari perbedaan-perbedaan yang telah dimiliki 
feminisme sejak awal. Mereka berkembang ketika mendapatkan konteks yang tepat saat perempuan mendefinisikan perbedaan di antara mereka. Perbedaan-perbedaan ini memperkaya feminisme dan mendorong feminisme untuk terus berkembang.

\section{DAFTAR PUSTAKA}

Bammer, Angelika. 1991. Partial Visions Feminism and Utopianism in the 1970s. New York dan London: Routledge

Braidotti, Rosi. "Feminist Philosophies" dalam $A$ Concise Companion to Feminist Theory editor Mary Eagleton. Melbourne: Blackwell Publishing. 2003.

Brooks, A. 1997. Brooks, Ann, 1997. Postfeminism: Feminism, Cultural Theory and Cultural Forms. London dan New York: Routledge

Budgeon. S. 2011a. Third-Wave Feminism and the Politics of Gender in Late Modernity. New Hampshire dan New York: Palgrave MacMillan.

Budgeon, S. 2011b. "The Contradictions of Successful Feminity: Third-wave Feminism, Postfeminism and 'New' Femininities" dalam New Femininities: Postfeminism, Neoliberalism and Subjectivity editor Rosalind Gill dan Christina Scharff. Hamphsire dan New York: Palgrave MacMillan. 2011.

De Beauvoir, S. 1956. The Second Sex. London: Lowe and Bryligne.

Faludi. S. 1991/2006. Backlash: The Undeclared War Against American Women. New York: Three Rivers Press.

Freidan, B. 1963. The Feminine Mystique. New York: Dell Publishing.

Gamble, S. 2006. "Postfeminism" dalam The Routledge Companion to Feminism and Postfeminism. Editor Sarah
Gamble. London and New York: Routedge.

Genz S. dan B. Brabon. 2009. Postfeminism: Cultural Text and Theories. Edinburgh: Edinburgh University Press

Gillis, S., G. Howie, dan R. Munford. 2004. "Introduction" dalam Third Wave Feminism: A Critical Exploration. Editor Stacy Gillis, Gillian Howie dan Rebecca Munford. Hampshire dan New York: Palgrave MacMillan.

Gills dan Schraff. 2011. Gill, Rosalind dan Christina Scharff. 2011. New Femininities: Postfeminism, Neoliberalism and Subjectivity. Hampshire dan New York: Palgrave MacMillan.

Gleadle, 2002 Kathryn Gleadle, 2002. Radical Writing on Women, 18001850. Hampshire and New York: Palgrave MacMillan.

Gubar, Susan. 2000. Critical Condition: Feminism at the Turn of the Century. New York: Columbia University Press.

Hewitt, N.A. 2010. "From Seneca Falls to Suffrage? Reimaginingg a "Master" Narrative I US Women's History" dalam No Permanent Waves: Recasting Histories of U.S. Feminism. New Brunswick, New Jersey, London: Rutgers Univerity Press

Hudgson-Wright, 2006. Hodgson-Wright, Early Feminism, dalam Cambridge Companion to Feminism and Postfeminism, Sarah Gamble (2006).

Jenainati Cathia dan Judy Groves, 2007. Introducing Feminism. Malta: Gutenberg Press.

Kirkham, M. 1997. Kirkham, Margaret. 1997. Jane Austen, Feminism, and Fiction. London and New Jersey: The Athole Press. 
McRobbie, A. 2009. The Aftermath of Feminism - Gender, Culture, and Social Change. London: SAGE Publications, Ltd.

McRobbie, A. 1994. McRobbie, Angela. 1994. Postmodernism and Popular Culture, New York: Routledge.

O'Brien, K. 2009. OWmen and Elightenment in Eighteenth-Century Britain. Cambridge: Cambridge University Press.

O'Reilly, A. dan M. Porter. 2005. "Introduction" dalam Motherhood: Power and Oppression. Editor Marie Porter, Patricia Short dan Andrea O'Reilly. Toronto: Women's Press.

Phoca, S dan R. Wright. 1999. Introducing Postfeminsim. Cambridge: Icon Books, Ltd.

Richardson, Alan. 2002. "Mary Wollstonecraft on Education" dalam The Cambridge Companion to Mary Wollstonecraft, editor Claudia I. Johnson. Cambridge: Cambridge University Press. 2002.

Ross, Sarah Gwyneth. 2009. The Birth of Feminism - Women as Intellect in renaissance Italy and England. Massachusetts dan London: Harvard University Press.

Sanders, Valerie. 2006. "First Wave Feminism" dalam Cambridge Companion to Feminism and Postfeminism, editor Sarah Gamble (2006).
Siegel, Deborah. 2007. Sisterhood Interrupted: From Radical Women to Grrls Gone Wild. Hampshire dan New York: Palgrave MacMillan

Thompson, Becky. 2010. "Multiracial Feminism: Recasting the Chronology of Second Wave Feminism" dalam No Permanent Waves- Recasting Histories of US Feminism editor Nancy Hewitt. New Brunswick, New Jersey, London: Rutgers University Press. 2010.

Thornham, S. 2006. "Feminism and Film" dalam The Routledge Companion to Feminism and Postfeminism. Editor Sarah Gamble. London and New York: Routedge.

Tong, R. 2009. Tong, Rosmarie. 2009. Feminist Thought: A More Comprehensive Introduction. $3^{\text {rd }}$ Edition. Colorado: Westview Press

Walters, Margaret. 2005. Feminism: A Very Short Introduction. New York: Oxford University Press

Whelehan, Imelda. 1995. Modern Feminist Thought - Second Wave to Postfeminism. Edinburgh: Edinburgh University Press.

Zaslow, 2009 Emilie Zaslow. 2009: Feminism, Inc. Coming of Age in Girl Power Media Culture. New York: Palgrave MacMillan.

Zeisler, A. 2008. Feminism and Popular Culture. California: Seal Press. 